\title{
Linkage between the Arctic Oscillation and summer climate extreme events over the middle reaches of Yangtze River Valley
}

\author{
Lu Liu ${ }^{1,2,3}$, Tong Zhou ${ }^{1,2,3}$, Liang Ning ${ }^{1,2,3,4,5,6,7, *}$, Jian Liu ${ }^{1,2,3,4}$, Mi Yan ${ }^{1,2,3,4}$, \\ Chunhan Jin ${ }^{1,2,3}$ and Weiyi Sun $^{1,2,3}$ \\ ${ }^{1}$ Key Laboratory for Virtual Geographic Environment, Ministry of Education, 210023, Nanjing, China \\ ${ }^{2}$ State Key Laboratory Cultivation Base of Geographical Environment Evolution of Jiangsu Province, \\ 210023, Nanjing, China \\ ${ }^{3}$ School of Geography, Nanjing Normal University, 210023, Nanjing, China \\ ${ }^{4}$ Jiangsu Center for Collaborative Innovation in Geographical Information Resource Development and Application, \\ 210023, Nanjing, China \\ ${ }^{5}$ Open Studio for the Simulation of Ocean-Climate-Isotope, Qingdao National Laboratory for Marine Science and \\ Technology, 266237, Qingdao, China \\ ${ }^{6}$ Climate System Research Center, Department of Geosciences, University of Massachusetts, 01003, Amherst, \\ United States \\ ${ }^{7}$ State Key Laboratory of Loess and Quaternary Geology, Institute of Earth Environment, Chinese Academy of Sciences, \\ 100000, Beijing, China
}

\begin{abstract}
The Arctic Oscillation (AO) is commonly recognized as a dominant large-scale mode influencing climate over the Northern Hemisphere. Here, the influences of May AO on summer (JJA) extreme precipitation events and summer extreme warm days over the middle reaches of Yangtze River Valley for the period 1961-2014 are investigated. Following a positive May AO, there are usually fewer summer extreme precipitation events but more summer extreme warm days over the middle reaches of Yangtze River Valley. Composite analyses show that positive May AO induces the northward displacement of the East Asian jet stream and northeastward displacement of the western Pacific subtropical high (WPSH), and causes a stronger, more northwestern subtropical northwest Pacific cyclone/anticyclone anomaly, as well as an anticyclonic circulation anomaly on the north side of the South China Sea, resulting in a northward shift of the rainfall belt and an enhancement of the East Asia summer monsoon. Therefore, the cumulative distribution probability of daily precipitation values shift significantly to a lower precipitation value, indicating lower probabilities of summer extreme precipitation events following positive May AO. A weakening of WPSH induces an anomalous sinking motion over the middle reaches of the Yangtze River Valley. The $850 \mathrm{hPa}$ wind field shows southerly wind anomalies over the Jiang-Huai River Basin, which cause a decrease in total cloud cover, resulting in an increase in solar radiation flux. A significant shift of the daily maximum temperature probability distribution towards to higher values indicates higher probabilities of summer extreme warm day occurrences following positive May AO. This study will provide useful insights to help improve the understanding of the dynamics and projections of future regional extreme precipitation changes over the middle reaches of Yangtze River Valley.
\end{abstract}

KEY WORDS: AO $\cdot$ Summer extreme precipitation events $\cdot$ Summer extreme warm days 


\section{INTRODUCTION}

In recent decades, the reduction of sea ice in the Arctic has caused amplified climate responses (Zhao et al. 2015), making the Arctic a focal area of climate change research (Tanaka \& Tamura 2016). As a dominant large-scale mode of climate variability, characterized by winds circulating counter-clockwise around the Arctic region (Thompson \& Wallace 1998), the Arctic Oscillation (AO) has attracted attention because of its important role in regional climate variability over the Northern Hemisphere (Wang 2004). Many studies have pointed out that the continued trend of the AO towards higher index values in recent decades is one of the important reasons leading to winter warming in the Northern Hemisphere (Thompson \& Wallace 2001). Over East Asia, the AO influences aspects of regional climate variability on multiple temporal scales (Shen et al. 2012, Park \& Ahn 2016, He et al. 2017). For example, a positive (negative) phase of winter AO usually causes a weaker (stronger) East Asian winter monsoon (EAWM) and corresponding warmer (colder) winters; this significant influence results from the AO's impact on the Siberian high (Gong et al. 2001, Wu \& Wang 2002). Park et al. (2011) indicate that the $\mathrm{AO}$ also has a significant relationship with cold surges over East Asia, finding that during a negative AO phase, cold surges are stronger in amplitude and duration. Furthermore, the state of the spring AO is also found to have significant influences on the East Asian summer monsoon (EASM) through shifts of the Asian summer jet stream (Gong et al. 2002), and on changes in north Pacific sea surface temperatures (SST) and the western North Pacific subtropical high (WNPSH) (Gong et al. 2011).

Besides the inter-annual variations, the inter-decadal variations of winter and summer climate over Asia are also profoundly influenced by the AO (Ding et al. 2014, He et al. 2017). For example, the transition of the AO from its negative phase to its positive phase after the mid-1980s might have contributed to weakening of the EAWM and inter-decadal warming over Eurasia (He 2015). Liu et al. (2017) summarized that the relationship of AO and EAWM is statistically significant during the 1928-1948 and 1975-1995 periods, with a robust positive phase of $\mathrm{AO}$ and upper-level convergence anomalies. Meanwhile, the relationship between spring AO and EASM on interannual timescale also shows a remarkable decadal variation in the late 1990s (Gao et al. 2014). Chen et al. (2015) found that the relationship between spring AO and EASM underwent a significant inter-decadal change in the early 1970s, with a weak relationship during the 1950s and 1960s and a strong and significant relationship from the mid-1970s through the mid-1990s. These influences on the inter-decadal scale are confirmed through Meiyu precipitation with annual time resolution, which was reconstructed based on the length of the monsoon rainy season over this region from 1736 to 2000 (Hao et al. 2015).

Eastern China, which is undergoing rapid economic and societal development, faces many challenges in understanding and adapting to the impacts of climate change. As a major part of the Asian monsoon region, many studies have confirmed that regional climate over eastern China is strongly influenced by the AO (Gong \& Wang 2003, Shen et al. 2012, Qu et al. 2015). During a negative phase of AO, the concurrent deeper East Asian trough and stronger Siberian high usually cause anomalously lower temperatures over eastern China (Gong et al. 2001). This relationship between winter AO and southeastern China air temperature shows intra-seasonal variation, due to the migrations of the Azores center of the AO (Zuo et al. 2015). Moreover, positive winter AO usually causes negative precipitation anomalies over northeastern China (He et al. 2017). However, a positive phase of the AO usually leads to above-average summer temperatures over eastern China (Huang et al. 2007). Previous studies (Gong et al. 2002, Gong \& Ho 2003) also revealed that summer precipitation over the Yangtze River Valley is strongly influenced by the spring AO through the EASM, with reduced precipitation during a positive phase of the AO. These relationships also show inter-decadal variation due to the inter-decadal changes in the relationship between the spring AO and the EASM (Chen et al. 2015).

Since 1951, with a background of global warming, the frequency and magnitude of extreme weather and climate events in China has notably increased (Gong et al. 2009, Ning \& Qian 2009, Wang \& Qian 2009, Ren et al. 2010, Ning et al. 2017), causing massive loss of life and property, especially across eastern China (Guo et al. 2013), leading to increasing societal attention. Ding et al. (2010) found that the number of winter extreme warm days and warm nights in most areas of northern China were larger during positive $\mathrm{AO}$ phases than during negative $\mathrm{AO}$ phases. Chen et al. (2013) also indicated that AO has a strong impact on the number of winter extreme warm and cold days over eastern China through variations of EAWM, both on inter-annual and inter-decadal scales.

Most previous studies (Gong et al. 2011, Lu et al. 2011, Mao et al. 2011, Chen et al. 2013, He 2015) mainly focused on the influence of AO on mean summer and winter climate, or on winter climate extreme 
events in China; however, relationships between $\mathrm{AO}$ and summer extreme climate events and corresponding physical mechanism have rarely been investigated. In this study, the influence of May AO on summer extreme precipitation events and summer extreme warm days over the middle reaches of Yangtze River Valley is examined. Detailed physical mechanisms connecting the negative AO phase and daily scale extreme events (Ning \& Bradley 2015a,b) are investigated. These analyses may help improve the understanding of mechanisms causing summer extreme climate events over the middle reaches of Yangtze River Valley and the future predictions on different scales, and may also help decision-makers better manage the mitigation of the impacts of increasingly frequent extreme climate events.

\section{DATA AND METHODOLOGY}

\subsection{Datasets}

The observational data of daily precipitation and maximum temperature were derived from the CN05.1 dataset provided by the China National Climate Center (CNCC, also known as Beijing Climate Center, BCC). As in the work by Xu et al. (2009), the CN05.1 dataset was modified using by the 'anomaly approach' during the interpolation, but with more station observations ( 2400) in China (Wu \& Gao 2013). The data cover an area from $14.75^{\circ}$ to $55.25^{\circ} \mathrm{N}$ and $69.75^{\circ}$ to $140.25^{\circ} \mathrm{E}$, with a resolution of $0.25^{\circ} \times$ $0.25^{\circ}$, from 1961 to 2014 .

The monthly AO index values were acquired from the Climate Prediction Center of the National Oceanic and Atmospheric Administration (NOAA/CPC, www. esrl.noaa.gov/) in May for the same time period.

The daily 200 and $850 \mathrm{hPa}$ horizontal and vertical wind speed components (u- and v-wind), $500 \mathrm{hPa}$ geopotential height, and $1000-500 \mathrm{hPa}$ omega field data with a resolution of $2.5^{\circ} \times 2.5^{\circ}$ for the period 1961-2014, derived from National Centers for Environmental Prediction (NCEP) Reanalysis I, were used for the composite analysis.

\subsection{Definition of summer extreme precipitation events and summer extreme warm days}

A summer extreme precipitation event was defined as a day with a daily precipitation above than the $90^{\text {th }}$ percentile of daily precipitation in summer (JJA) during the whole 1961-2014 period. A summer extreme warm day was defined as a day with a daily maximum temperature above than the $90^{\text {th }}$ percentile of daily maximum temperature in the same month during the 1961-2014 period. Finally, the total number of each extreme event in the entire season was calculated.

The definitions of these extreme indices have been commonly used in previous studies of climate extremes (Ning \& Bradley 2015a,b). These two indices help inform a wide range of regional inter-disciplinary research topics, which are also of increasing concerns due the potential impacts of future climate change on society and economy (Easterling et al. 2000, Meehl et al. 2000, Ning et al. 2015).

\section{RESULTS}

\subsection{Correlation between May AO and summer extreme climate events}

To examine the lag-relationships between $\mathrm{AO}$ and summer extreme precipitation events and summer extreme warm days, linear correlation coefficients between $\mathrm{AO}$ and the number of summer extreme precipitation events and warm days were calculated. This showed that the correlation between May AO and number of summer extreme precipitation events and summer extreme warm days was the most significant one. The spatial patterns of the correlations are shown in Fig. 1. It can be seen that the May AO has significant negative correlations with number of summer extreme precipitation events over the middle reaches of Yangtze River Valley $\left(27^{\circ}-31^{\circ} \mathrm{N}\right.$, $110^{\circ}-119^{\circ} \mathrm{E}$ ) (Fig. 1a), which is similar to rainfall correlation (He et al. 2017). The correlation between the May AO and number of summer extreme warm days over the middle reaches of Yangtze River Valley are positive, and most of them are significant (Fig. 1b), as proposed by $\mathrm{He}$ et al. (2017). This indicates that when May AO is in positive status, there are usually fewer summer extreme precipitation events but more summer extreme warm days over the middle reaches of Yangtze River Valley.

Fig. 2 shows the standardized time series of the May AO and the number of summer extreme precipitation events and summer extreme warm days. The area average is calculated for the middle reaches of Yangtze River Valley with the most significant correlations with May AO. Considering the impact of global warming on the data, the detrended time series of the number of summer extreme warm days is presented in Fig. 2b. May AO has a significant 


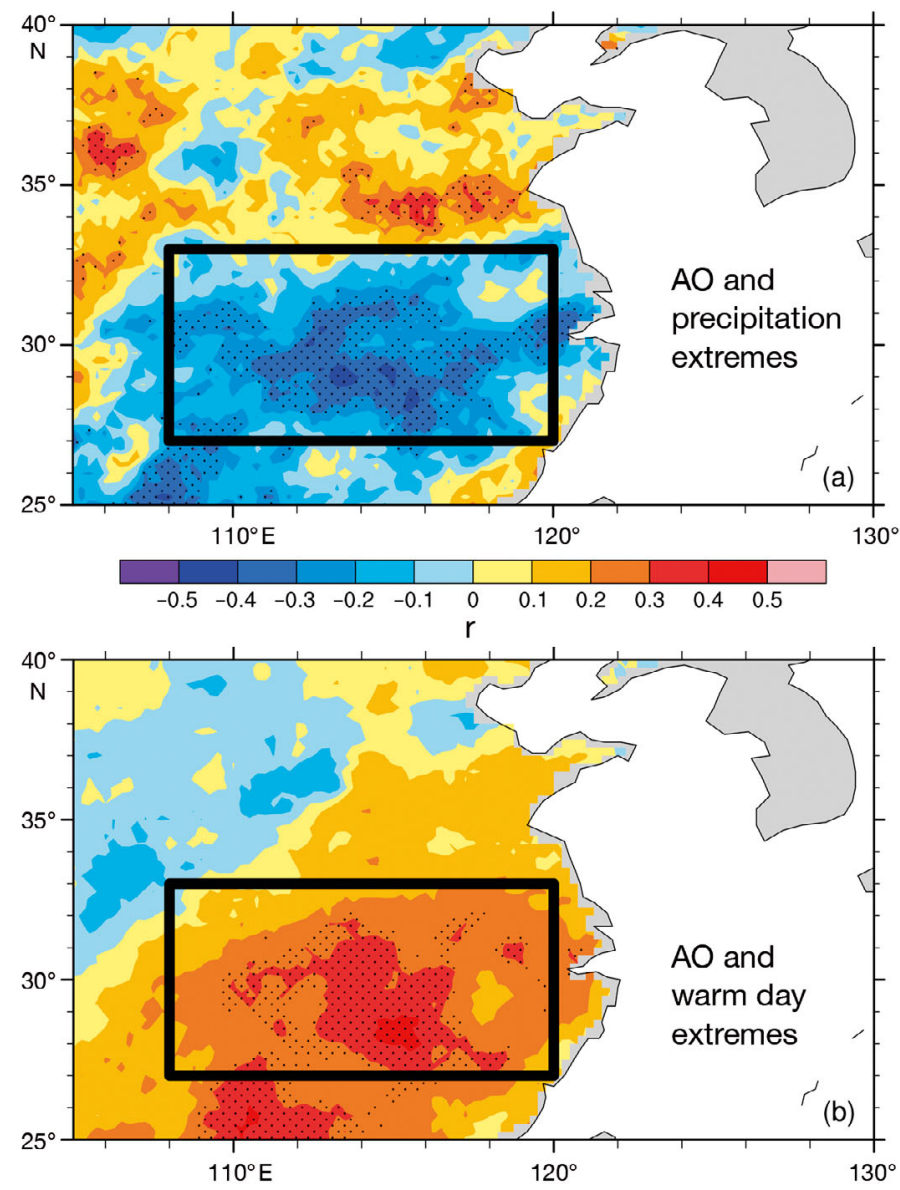

Fig. 1. Spatial patterns of correlation coefficients (r) between May AO and (a) number of summer extreme precipitation events, and (b) number of summer extreme warm days negative correlation with the number of summer extreme precipitation events $(\mathrm{r}=-0.40, \mathrm{p}<0.01)$, and a significant positive correlation with the number of summer extreme warm days $(\mathrm{r}=0.35, \mathrm{p}<0.01)$. This indicates that May AO can possibly modulate the inter-annual variability of summer extreme precipitation events and summer extreme warm days over the middle reaches of Yangtze River Valley. When May $\mathrm{AO}$ is in the positive phase, there are usually fewer summer extreme precipitation events and more summer extreme warm days over the middle reaches of the Yangtze River Valley. These correlations are consistent with previous studies on the influences of preceding spring $\mathrm{AO}$ on the average summer precipitation (Gong et al. 2002) and temperature (Huang et al. 2007) over the eastern China.

To investigate the physical mechanisms behind the correlations between May AO and summer extreme climate events over the middle reaches of Yangtze River Valley, the differences of the circulation fields between years with positive and negative May AO phases relative to precipitation anomalies or extreme warm events are examined in the following composite analysis.

\subsection{Mechanisms}

Dekyi-Pedron et al. (2017) found that the AO directly influences the surface temperature, sea-level pressure (SLP), $500 \mathrm{hPa}$ geopotential height and the
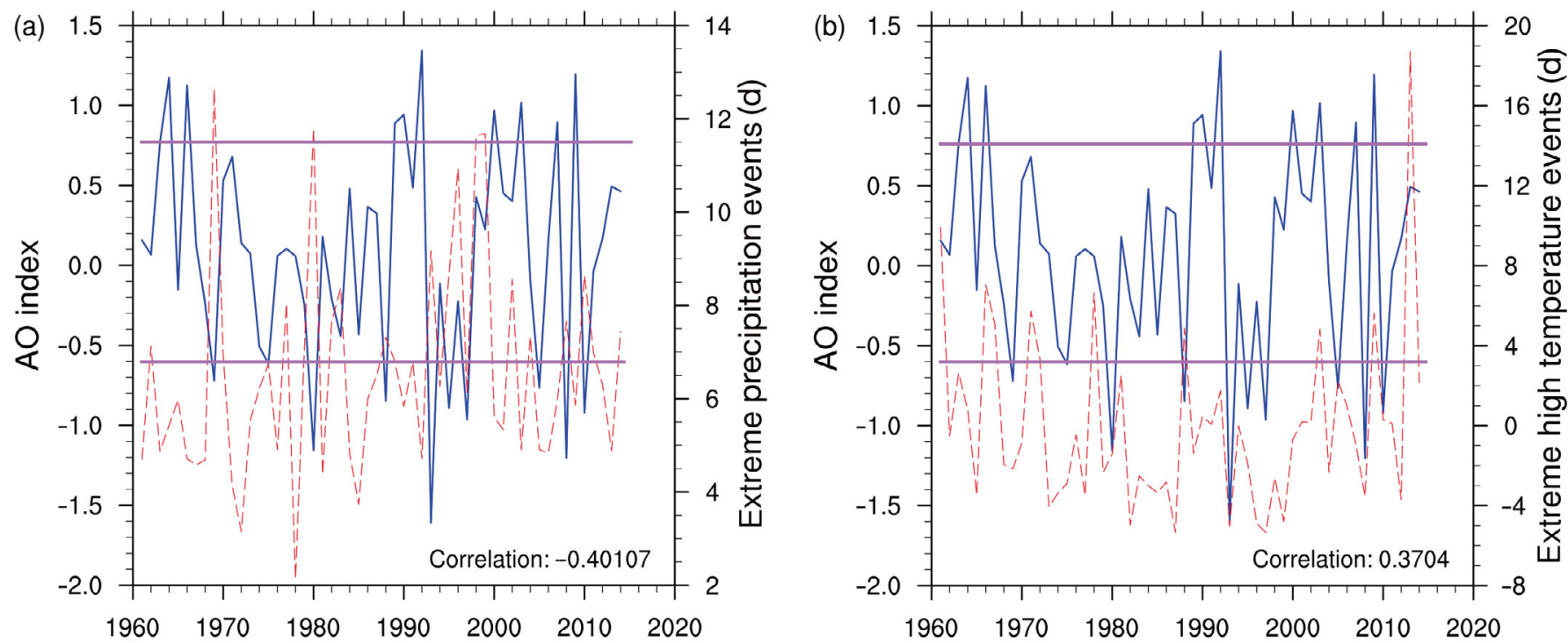

Fig. 2. Time series of May AO index (blue solid line) and May AO index standard deviation (purple solid lines) as well as (a) number of summer extreme precipitation events (red dashed line); and (b) number of summer extreme warm days (red dashed line) over the middle reaches of Yangtze River Valley 
850 hpa wind field. In this section, the differences of the averaged summer extreme precipitation events and summer extreme warm days daily $200 \mathrm{hPa}$ zonal wind, $850 \mathrm{hPa}$ u-winds and v-winds, $500 \mathrm{hPa}$ geopotential height, low-level omega field (1000-500 hPa) and downward solar radiation flux data between the high-AO (>1 SD) and low-AO (<1 SD) years are first calculated. Then, the responses of daily precipitation and warm days are investigated through the changes in the probability distributions.

Table 1 shows the years with high and low AO. High-AO years are defined as a May with $\mathrm{AO}>1 \mathrm{SD}$. Low-AO years are defined as a May with $\mathrm{AO}<1 \mathrm{SD}$. For this analysis, 10 high-AO and 10 low-AO years were selected.

In order to analyze the physical mechanism of $\mathrm{AO}$ impact on summer climate extreme events, we calculate the difference of the daily average summer climate extreme events between the high-AO and low-AO years, according to the formula: variable I (daily average summer climate extreme events during high-AO years) - variable I (daily average summer climate extreme events during low-AO years).

\subsubsection{May AO influence on summer extreme precipitation events}

Previous studies have revealed that 2 large-scale circulation systems in summer, i.e. the East Asian jet stream (EAJS) and western Pacific subtropical high (WPSH), dominate the EASM that directly influence the summer precipitation over eastern China, especially over the lower and middle reaches of Yangtze River Valley (Gong \& Ho 2003). The variabilities of these 2 large-scale circulation systems are both significantly correlated with the preceding spring AO (He et al. 2017). A positive phase of May AO usually leads to a northward shift of summer EAJS, with a simultaneous northward shift of the rain belt, resulting in drier conditions over the middle reaches of the Yangtze River Valley (Gong et al. 2002). This northward shift of summer EAJS is also reflected in zonal wind anomalies at $200 \mathrm{hPa}$ (Fig. 3a), namely the significant negative anomalies locating over $30^{\circ} \mathrm{N}$ and significant positive anomalies locating over $\sim 45^{\circ} \mathrm{N}$, indicating that the EAJS core shifts northward about

Table 1. Years with high and low AO anomalies

High 1963, 1964, 1966, 1989, 1990, 1992, 2000, 2003, 2007, 2009 Low 1969, 1975, 1980, 1988, 1993, 1995, 1997, 2005, 2008, 2010 by $\sim 15^{\circ}$. The northward shift of the EAJS plays an important role in the tropical convective anomalies that affect the tropical outer circulation: after the EAJS shifts northward, the tropical western Pacific atmospheric convection anomalies can ignite a stronger, northwest-shifted subtropical northwest Pacific cyclone/anticyclone anomaly, which leads to a northward shift of precipitation anomalies in East Asia (Ye \& Lu 2011).

The $500 \mathrm{hPa}$ geopotential height anomalies (Fig. 3b) shows that a weaker WPSH usually follows a positive phase of May AO, similar to the pattern found in monthly data (Gong et al. 2011). Meanwhile, we find that the WPSH moved to the northeast during the high-AO years. When the WPSH shifts to the northeast, anomalous cyclonic circulation occurs near the South China Sea, and the north side of the South China Sea shows an anticyclonic circulation anomaly, strengthening the East Asian summer monsoon (Yu et al. 2014). This northeastward shift of the WPSH results in an enhanced EASM, correspondingly less convergence over the middle reaches of the Yangtze River Valley, and more convergence over the northern part of eastern China due to moist warm advection and cold dry advection, respectively (Ning et al. 2017).

Both the northward shift of the EASJ and the northeastward shift of the WPSH induce anomalous water sinking motion (Fig. 3c) over the middle reaches of the Yangtze River Valley, resulting in a decrease in the number of summer extreme precipitation events over the middle reaches of the Yangtze River.

\subsubsection{May AO's influences on the summer extreme warm days}

When the May AO is in the positive phase, the WPSH is anomalously weaker (Fig. 4a). This geopotential height pattern induces the significant downward movement (Fig. 4b). Moreover, there are southerly wind anomalies over the Jiang-Huai River Basin (Fig. 4c), which reduces the total cloud cover (Fig. 4d), and finally brings more solar radiation to the surface with anomalies $>5 \mathrm{~W} \mathrm{~m}^{-2}$ (Fig. 4e). These significant increases in solar radiation flux also cause positive temperature anomalies, and leads to higher temperatures over central South China, a finding also reported by Ye et al. (2013).

The detailed mechanisms behind the May AO influence on EASM variability through the summer EAJS and WPSH are still an open scientific question. Some potential mechanisms have been hypothe- 

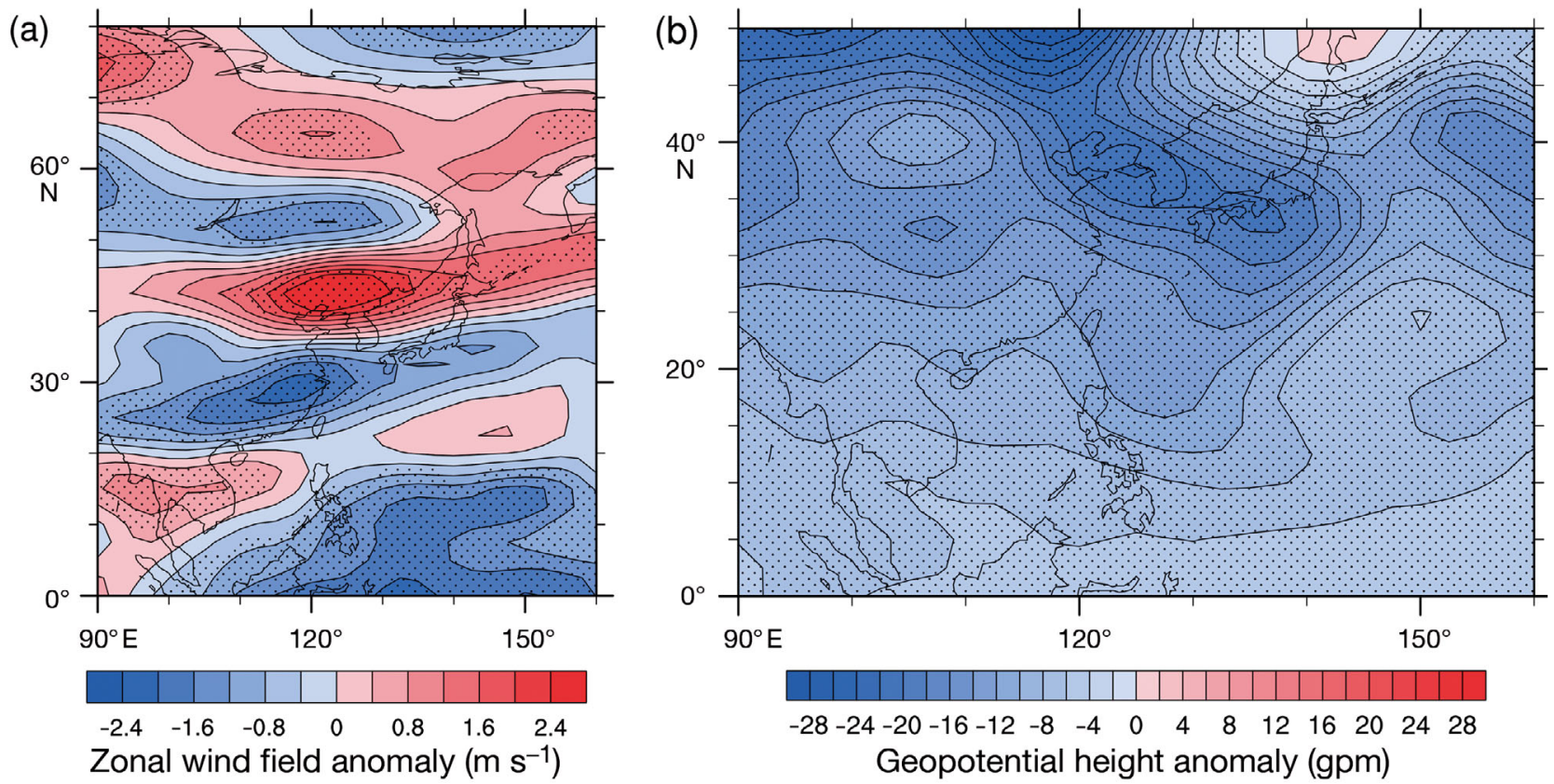

Fig. 3. Anomalies of (a) $200 \mathrm{hPa}$ zonal wind field; (b) $500 \mathrm{hPa}$ geopotential height anomaly; and (c) lowlevel $(1000 \mathrm{hPa}$ to $500 \mathrm{hPa})$ vertical velocity between summer extreme precipitation events following high and low May AO. The stippling indicates differences significant at the $p<0.05$ level

sized; for example, He et al. (2017) summarize in their review that changes in soil moisture, as well as SST changes over the North Atlantic, Indian Ocean and North Pacific, are the pathways through which spring AO affects the EASM. Investigating how the AO influences the EAJS, Gong et al. (2002) suggested that possible mechanisms include jet stream-tropical SST interaction, the AO signal's downward propagation from the stratosphere, wave-mean flow interaction, and

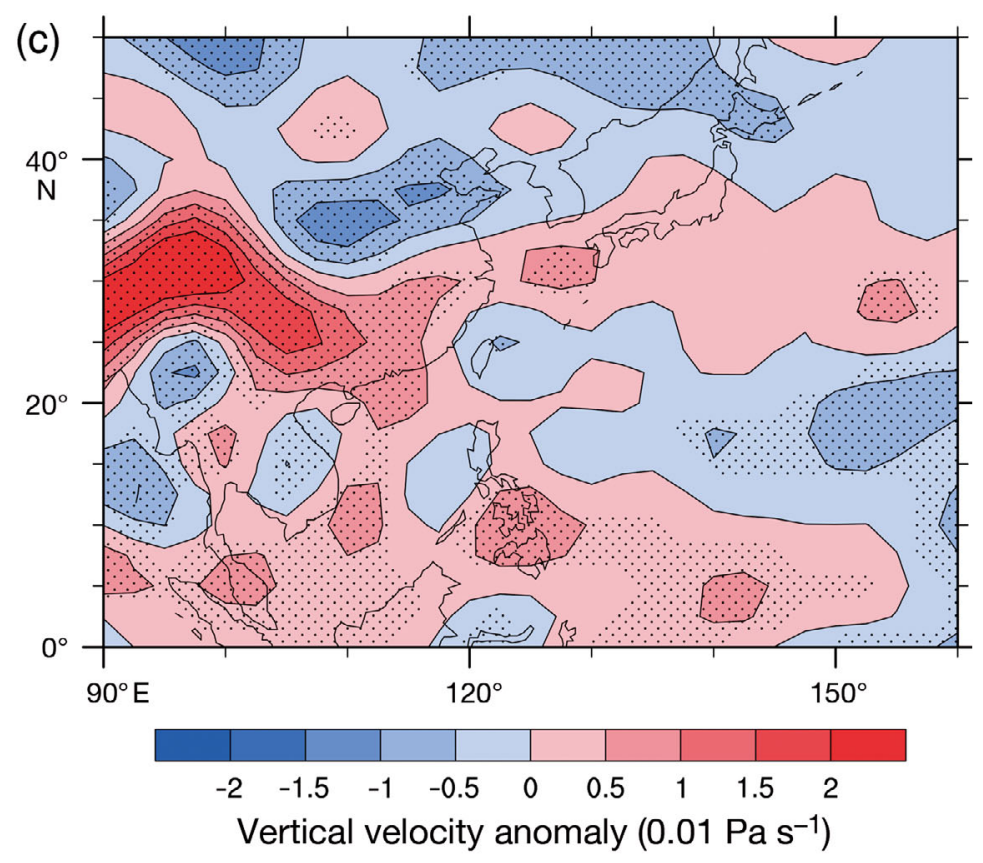
land surface process-atmosphere interaction. Using both observational data and model simulations, Gong et al. (2011) found that the AO-associated atmospheric circulation change over the north Pacific produces positive SST anomalies, which intensify the cyclone-like circulation over the western North Pacific through a Gill-type response, and finally influence the monsoon trough and the WPSH. Moreover, the upper troposphere wave-train pattern associated with the AO may also contribute to regional climate variability over eastern Asia (Ha et al. 2012).

\subsection{Responses of daily variables}

To examine the responses of daily precipitation and maximum temperature to the seasonal-scale synoptic circulation anomalies due to the May AO variability, changes in the probability distributions of daily precipitation and maximum temperature due to differences of seasonal mean synoptic circulation patterns are investigated in this section.

Fig. 5 compares the cumulative distributions (Fig. 5a) and the probability distributions (Fig. 5b) 

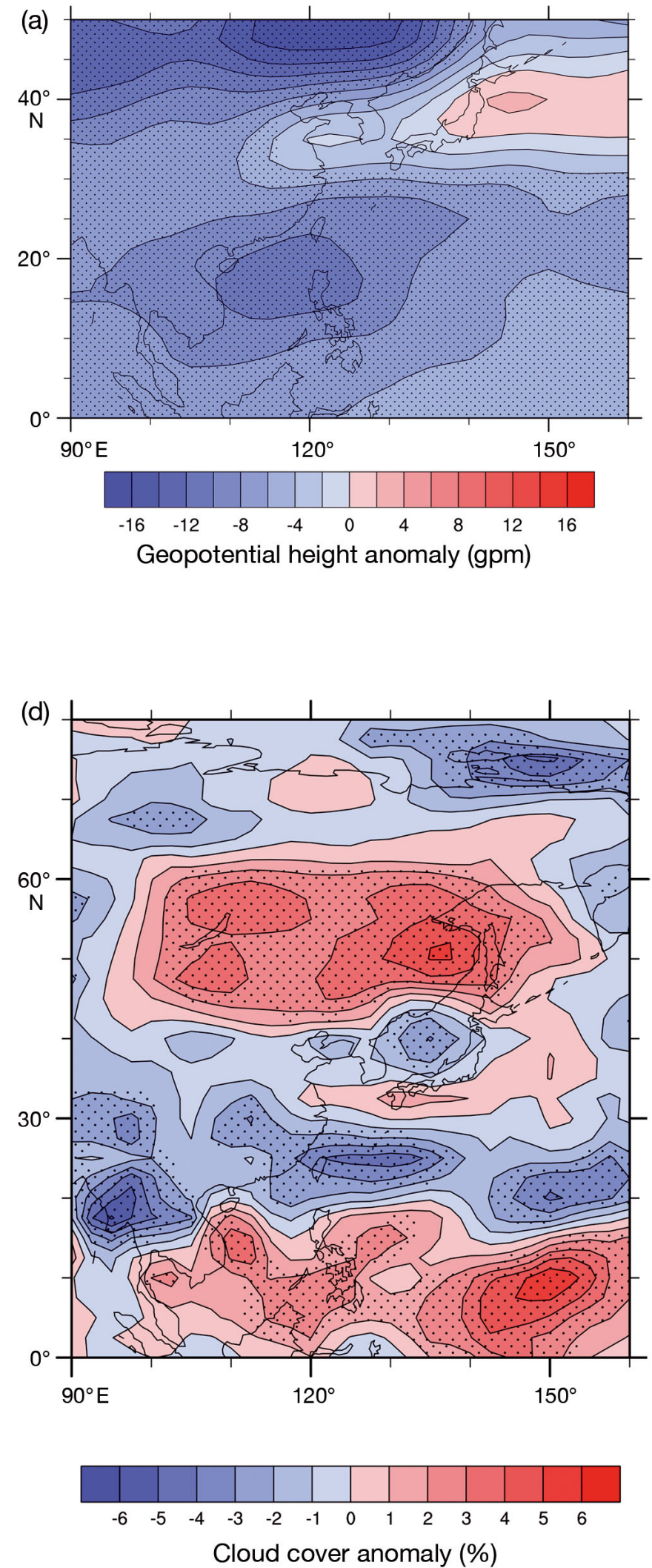
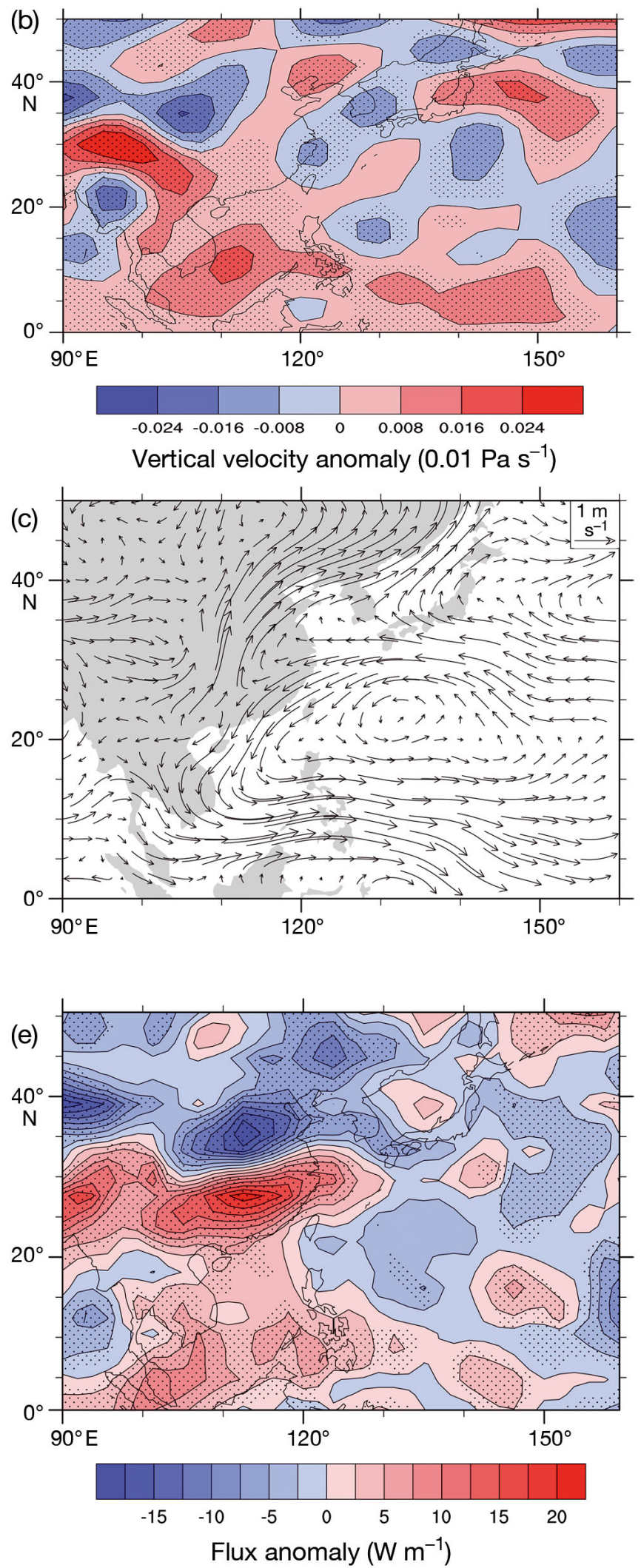

Fig. 4. Anomalies of (a) $500 \mathrm{hPa}$ geopotential height anomaly; (b) low-level (1000 hPa to $500 \mathrm{hPa}$ ) vertical velocity; (c) $850 \mathrm{hPa}$ wind field; (d) total cloud cover; and (e) surface downward solar radiation flux of summer extreme warms days between high and low May AO 

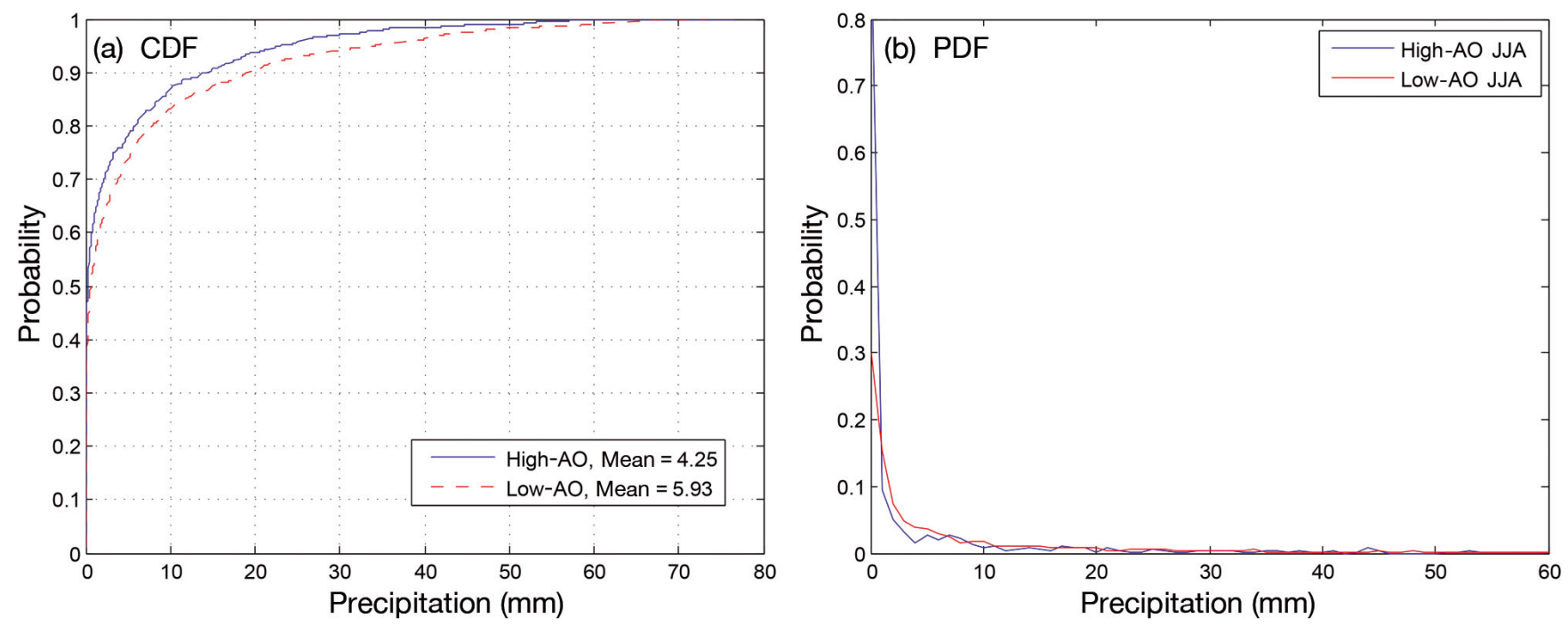

Fig. 5. (a) Cumulative distribution and (b) probability distribution functions of daily precipitation over the representative location (the middle reaches of the Yangtze River Valley: $27^{\circ}-31^{\circ} \mathrm{N}, 110^{\circ}-119^{\circ} \mathrm{E}$ ) between summers following high May AO (blue solid line) and the summers following low May AO (red dashed line)

of daily average precipitation during the years with high- and low-AO indices over the area (the middle reaches of the Yangtze River Valley: $27^{\circ}-31^{\circ} \mathrm{N}$, $110^{\circ}-119^{\circ} \mathrm{E}$ ) which are significantly correlated. During high-AO years, the probability of daily precipitation shifts leftward compared with low-AO years, indicating a lower probability of extreme precipitation events. At the same time, we compared the average, standard deviation, skewness and kurtosis of summer daily precipitation under high-AO and low-AO (Table 2). We find that the average $(5.93 \mathrm{~mm})$ and $\mathrm{SD}(2.44 \mathrm{~mm})$ during the low-AO years are higher than the average $(4.25$ $\mathrm{mm})$ and SD $(2.06 \mathrm{~mm})$ during the high-AO years. When a Student's $t$-test is applied, the average of the daily precipitation during high-AO years is significantly smaller than the average during the lowAO years $(p<0.01)$. Similarly, we found that the skewness (2.99) and kurtosis (9.74) during the low$\mathrm{AO}$ years are greater than the skewness (2.65) and kurtosis (7.93) during the high-AO years, indicating that there are more summer extreme precipitation events during the low-AO years.

Table 2. Average, SD, skewness and kurtosis of summer daily precipitation under high-AO and low-AO anomalies

\begin{tabular}{|lcccc|}
\hline & Average & SD & Skewness & Kurtosis \\
\hline High-AO & 4.25 & 2.06 & 2.65 & 7.93 \\
Low-AO & 5.93 & 2.44 & 2.99 & 9.74 \\
\hline
\end{tabular}

The cumulative distributions (Fig. 6a) and probability distributions (Fig. 6b) of daily maximum temperature during the years with high-AO and low-AO indices over the area are shown in Fig. 6. The probability distribution of daily maximum temperature during high-AO years shifts to the right compared with low-AO years, indicating a lower probability of days with higher maximum temperature, while mean temperature of high-AO is prominently higher than that of low-AO in summer. The average, SD, skewness and kurtosis of daily maximum temperature distributions are calculated in Table 3. During high-AO years, the average $\left(32.50^{\circ} \mathrm{C}\right)$ and $\mathrm{SD}\left(5.70^{\circ} \mathrm{C}\right)$ are higher than the average $\left(31.13^{\circ} \mathrm{C}\right)$ and $\mathrm{SD}\left(5.57^{\circ} \mathrm{C}\right)$ during low-AO years. Moreover, when Student's $t$-test is applied, the average of daily maximum temperature during the high-AO years is significantly larger than the average during the low-AO years $(\mathrm{p}<0.01)$. The higher skewness (-3.22) and kurtosis (19.45) compared to the skewness (-3.26) and kurtosis (19.37) during the low$\mathrm{AO}$ years indicate more summer extreme warm days.

Based on the analysis of the mean, standard deviation, skewness and kurtosis of the daily precipitation

Table 3. Average, SD, skewness and kurtosis of summer daily maximum temperature under high-AO and low-AO anomalies

\begin{tabular}{|lcccc|}
\hline & Average & SD & Skewness & Kurtosis \\
\hline High-AO & 32.50 & 5.70 & -3.22 & 19.45 \\
Low- AO & 31.13 & 5.57 & -3.26 & 19.37 \\
\hline
\end{tabular}


(a) CDF

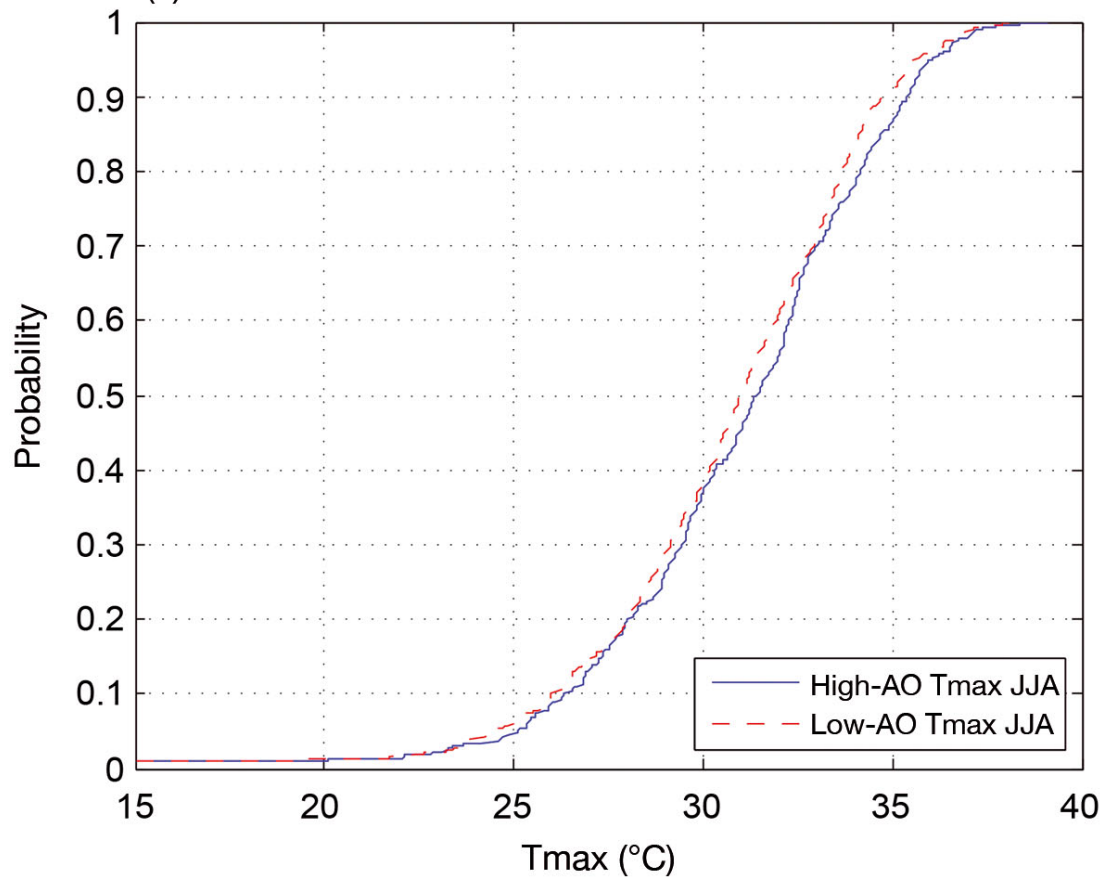

(b) PDF

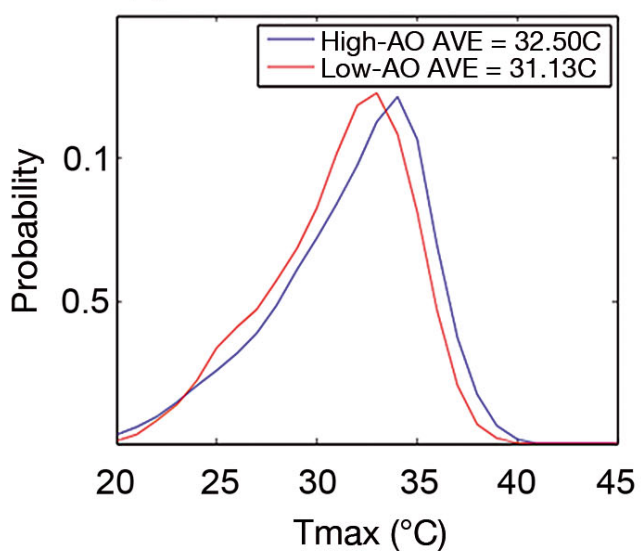

Fig. 6. (a) Cumulative distributions and (b) probability distribution of daily maximum temperature between the summers following high May AO (blue solid lines) and the summers following low May AO (red solid line) and the daily maximum temperature during high-AO and low-AO years, we found that the influence of May AO on summer extreme precipitation events and summer warm days is dominated by change, which cause the daily precipitation (daily maximum temperature) to move to lower (higher) values.

\section{DISCUSSION AND CONCLUSIONS}

In this study, the correlations between May AO, summer extreme precipitation events, and summer extreme warm days over the middle reaches of Yangtze River Valley, and the corresponding physical mechanisms, were investigated. The results show that May AO has significant negative correlations with summer extreme precipitation events, but significant positive correlations with summer extreme warm days over the middle reaches of Yangtze River Valley, similar to results of previous studies focusing on summer mean precipitation and temperature (Gong et al. 2002, Huang et al. 2007, He et al. 2017).

Composite analyses show that during summers that follow a positive phase of May AO, the EAJS shifts to the north and the WPSH shifts to the northeast, resulting in an enhancement of the EASM and a northward displacements of the rain belt. These changes of synoptic circulation fields induce the cumulative distribution probability of daily precipitation to shift significantly to smaller values, indicating a lower probability of extreme precipitation occurrences following a positive phase of May AO.

Meanwhile, the weakening of the WPSH and the southerly wind anomalies over the Jiang-Huai River Basin result in positive solar radiation flux anomalies. The enhanced solar radiation induces the daily maximum temperature to increase significantly, indicating a higher probability of warm day occurrences following a positive phase of May AO.

The findings in this study can help to improve the understanding of variability and mechanisms of summer extreme climate events over the middle reaches of Yangtze River Valley. Our findings can also contribute to more accurate short-term predictions and long-term projections of summer extreme events, and help decision-makers to prepare corresponding adaptions and the mitigation of the socio-economic impacts of future climate change.

The mechanism behind May AO and summer extreme precipitation events and summer extreme warm days are investigated in this study; however, the detailed mechanisms linking the May AO and summer EAJS and WPSH are not well understood, e.g. the AO signal's downward propagation from the stratosphere and the wave-mean flow interaction (Gong et al. 2002), which should be investigated in future work. 
Acknowledgements. This study was jointly supported by the National Basic Research Program of China (Grant No. 2016YFA0600401), the National Natural Science Foundation of China (Grant Nos. 41971021, 41420104002, 41671197, and 41631175), Open Funds of State Key Laboratory of Loess and Quaternary Geology, Institute of Earth Environment, Chinese Academy of Sciences (SKLLQG1820). We thank Dr. Bin Wang from University of Hawaii for the valuable insights and suggestions. Dr. Jia Wu from the National Climate Center, China Meteorological Administration, kindly provided the high-resolution observation data (CN05.1 data). More details about this data can be found at $\mathrm{Wu}$ and Gao (2013). The AO index and the NCEP Reanalysis data were provided by the NOAA/CPC and NOAA/OAR/ESRL PSD, Boulder, Colorado, USA, from their website at www. esrl.noaa.gov/psd/.

\section{LITERATURE CITED}

Bingyi W, Wang J (2002) Possible impacts of winter Arctic oscillation on Siberian high, the East Asian winter monsoon and sea-ice extent. Adv Atmos Sci 19:297-320

* Chen S, Chen W, Wei K (2013) Recent trends in winter temperature extremes in eastern China and their relationship with the Arctic Oscillation and ENSO. Adv Atmos Sci 30:1712-1724

* Chen S, Chen W, Wu R (2015) An interdecadal change in the relationship between boreal spring Arctic Oscillation and the East Asian summer monsoon around the early 1970s. J Clim 28:1527-1542

Dekyi-Pedron D, Drolma, Li QX (2017) Characteristic of annual variation of East Asian Winter Monsoon (EAWM) and its relationship with Arctic Oscillation (AO). J Tibet Univ 32:109-122 (in Chinese)

Ding YY, Liao QL, Wang Y (2010) Variations of the winter extreme temperature over northern China and their relationships with the Arctic Oscillation. J Arid Land Resour Environ 24:95-101

Ding Y, Liu Y, Liang S, Ma X and others (2014) Interdecadal variability of the East Asian winter monsoon and its possible links to global climate change. J Meteorol Res 28:693-713

Easterling DR, Meehl GA, Parmesan C, Changnon SA, Karl TR, Mearns LO (2000) Climate extremes: observations, modeling, and impacts. Science 289:2068-2074

Gao MN, Yang J, Gong DY, Kim SJ (2014) Unstable relationship between spring Arctic Oscillation and East Asian summer monsoon. Int J Climatol 34:2522-2528

Gong D, Ho CH (2003) Arctic oscillation signals in East Asian summer monsoon. J Geophys Res 108:4066

Gong DY, Wang S (2003) Influence of Arctic Oscillation on winter climate over China. J Geogr Sci 13:208-216

*Gong DY, Wang SW, Zhu JH (2001) East Asian winter monsoon and Arctic oscillation. Geophys Res Lett 28: 2073-2076

Gong DY, Zhu JH, Wang SW (2002) Significant relationship between spring $\mathrm{AO}$ and the summer rainfall along the Yangtze River. Chin Sci Bull 47:948-952 (in Chinese)

Gong ZQ, Wang SW, Zhi R, Feng GL (2009) Regional characteristics of temperature changes in China during the past 58 years and its probable correlation with abrupt temperature change. Acta Physica Sinica 58:4342-4353 (in Chinese)

Gong DY, Yang J, Kim SJ, Gao YQ, Guo D, Zhou T, Hu M (2011) Arctic Oscillation-East Asian summer monsoon connection through circulation changes over the western North Pacific. Clim Dyn 37:2199-2216

Guo X, Wang ZW, Yu SB, Guo YX (2013) Precipitation and variations of extreme drought/flood events in the Eastern China in the 20th century. J Arid Meteorol 31:476-481

*Ha KJ, Chu JE, Lee JY, Wang B, Hameed SN, Watanabe M (2012) What caused the cool summer over northern Central Asia, East Asia and central North America during 2009? Environ Res Lett 7:044015

*Hao Z, Sun D, Zheng J (2015) East Asian monsoon signals reflected in temperature and precipitation changes over the past 300 years in the middle and lower reaches of the Yangtze River. PLOS ONE 10:e0131159

*He SP (2015) Asymmetry in the Arctic oscillation teleconnection with January cold extremes in Northeast China. Atmos Ocean Sci Lett 8:386-391

He S, Gao Y, Li F, Wang H, He Y (2017) Impact of Arctic Oscillation on the East Asian climate: a review. Earth Sci Rev 164:48-62

* Huang J, Tan B, Suo L, Hu Y (2007) Monthly changes in the influence of the Arctic Oscillation on surface air temperature over China. Adv Atmos Sci 24:799-807

Liu Y, He S, Li F, Wang H, Zhu Y (2017) Interdecadal change between the Arctic Oscillation and East Asian climate during 1900-2015 winters. Int J Climatol 37:4791-4802

Lu LY, Bian LG, Zhang ZQ (2011) Climate Change and its impact on the Polar and the Tibetan Plateau Regions. Chin J Polar Res 2:82-89 (in Chinese)

* Mao R, Gong DY, Yang J, Bao JD (2011) Linkage between the Arctic Oscillation and winter extreme precipitation over central-southern China. Clim Res 50:187-201

*Meehl GA, Karl T, Easterling DR, Changnon S and others (2000) An introduction to trends in extreme weather and climate events: observations, socioeconomic impacts, terrestrial ecological impacts, and model projections. Bull Am Meteorol Soc 81:413-416

Ning L, Bradley RS (2015a) Winter climate extremes over the northeastern United States and southeastern Canada and teleconnections with large-scale modes of climate variability. J Clim 28:3289-3310

Ning L, Bradley RS (2015b) Influence of Eastern Pacific and Central Pacific El Niño events on winter climate extremes over the eastern and central United States. Int J Climatol 35:4756-4770

*Ning L, Qian Y (2009) Interdecadal change of extreme precipitation over South China and its mechanism. Adv Atmos Sci 26:109-118

Ning L, Riddle EE, Bradley RS (2015) Projected changes in climate extremes over the northeastern United States. J Clim 28:2475-2493

Ning L, Liu J, Wang B (2017) How does the South Asia High influence extreme precipitation over the eastern China? J Geophys Res Atmos 122:4281-4298

* Park HJ, Ahn JB (2016) Combined effect of the Arctic Oscillation and the Western Pacific pattern on East Asia winter temperature. Clim Dyn 46:3205-3221

* Park TW, Ho CH, Yang S (2011) Relationship between the Arctic Oscillation and cold surge over East Asia. J Clim 24:68-83

Qu JX, Gong DY, Li S (2015) The possible influence of Arctic Oscillation on South China Sea climate during boreal spring. Chin Sci Bull 60:2327 (in Chinese)

Ren GY, Feng GL, Yan ZW (2010) Progress in observation studies of climate extremes and changes in mainland China. Clim Environ Res 15:337-353 
Shen BZ, Lian Y, Zhang SX, Li SF (2012) Impacts of Arctic Oscillation and Polar Vortex anomalies on winter temperature over Eurasian continent. Clim Change Res 8:434-439

* Tanaka HL, Tamura M (2016) Relationship between the Arctic oscillation and surface air temperature in multidecadal time-scale. Polar Sci 10:199-209

Thompson DW, Wallace JM (1998) The Arctic Oscillation signature in the wintertime geopotential height and temperature fields. Geophys Res Lett 25:1297-1300

Thompson DW, Wallace JM (2001) Regional climate impacts of the Northern Hemisphere annular mode. Science 293: 85-89

Wang XH (2004) On atmosphere activities and dynamic mechanism of Arctic Oscillation. Jiangsu University (doctoral dissertation)

Wang ZF, Qian YF (2009) Frequency and intensity of extreme precipitation events in China. Adv Water Sci 20(1) (in Chinese with English abstract)

Wu J, Gao XJ (2013) A gridded daily observation dataset over China region and comparison with the other datasets. Chin J Geophys 56:1102-1111 (in Chinese with English abstract)

Xu Y, Gao XJ, Shen Y, Xu CH, Shi Y, Giorgi F (2009) A daily

Editorial responsibility: Ricardo Trigo,

Lisbon, Portugal temperature dataset over China and its application in validating a RCM simulation. Adv Atmos Sci 26:763-772

*Ye H, Lu R (2011) Subseasonal variation in ENSO-related East Asian rainfall anomalies during summer and its role in weakening the relationship between the ENSO and summer rainfall in eastern China since the late 1970s. J Clim 24:2271-2284

Ye DX, Yin JF, Chen ZH, Zheng YF, Wu RJ (2014) Spatial and temporal variations of heat waves in China from 1961 to 2010. Adv Clim Chang Res 5:66-73

Yu DD, Zhang R, Zhao YC, Wan L, Guo XX (2014) The interaction and correlation between the east-west advance and retreat of the West Pacific subtropical high and the East Asian summer monsoon system. Trans Atmos Sci 37:304-312

Zhao JP, Shi JX, Wang ZM, Li ZJ, Huang F (2015) Arctic amplification produced by sea ice retreat and its global climate effects. Adv Earth Sci 30:985-995 (in Chinese with English abstract)

Zuo JQ, Ren HL, Li WJ (2015) Contrasting impacts of the Arctic Oscillation on surface air temperature anomalies in southern China between early and middle-to-late winter. J Clim 28:4015-4026

Submitted: May 22, 2018; Accepted: October 22, 2018 Proofs received from author(s): February 4, 2019 